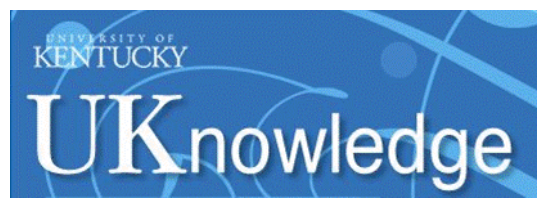

University of Kentucky

UKnowledge

\title{
Psychosocial Factors Related to the Intergenerational Transmission of Externalizing Behaviors in Early Midlife
}

\author{
Chenshu Zhang \\ New York University \\ Judith S. Brook \\ New York University \\ Neo K. Morojele \\ Medical Research Council, South Africa \\ Mario De La Rosa \\ Florida International University \\ Carl G. Leukefeld \\ University of Kentucky, cleukef@uky.edu
}

See next page for additional authors

Follow this and additional works at: https://uknowledge.uky.edu/behavsci_facpub

Part of the Behavior and Behavior Mechanisms Commons, and the Substance Abuse and Addiction

Commons

Right click to open a feedback form in a new tab to let us know how this document benefits you.

\section{Repository Citation}

Zhang, Chenshu; Brook, Judith S.; Morojele, Neo K.; De La Rosa, Mario; Leukefeld, Carl G.; and Brook, David W., "Psychosocial Factors Related to the Intergenerational Transmission of Externalizing Behaviors in Early Midlife" (2017). Behavioral Science Faculty Publications. 48.

https://uknowledge.uky.edu/behavsci_facpub/48

This Article is brought to you for free and open access by the Behavioral Science at UKnowledge. It has been accepted for inclusion in Behavioral Science Faculty Publications by an authorized administrator of UKnowledge. For more information, please contact UKnowledge@lsv.uky.edu. 


\section{Psychosocial Factors Related to the Intergenerational Transmission of Externalizing Behaviors in Early Midlife}

\section{Digital Object Identifier (DOI)}

https://doi.org/10.1080/10826084.2016.1276601

\section{Notes/Citation Information}

Published in Substance Use \& Misuse, v. 52, issue 10, p. 1328-1337.

(C) 2017 Taylor \& Francis Group, LLC

The copyright holder has granted the permission for posting the article here.

This is an Accepted Manuscript of an article published by Taylor \& Francis in Substance Use \& Misuse on 10 Apr 2017, available online: http://www.tandfonline.com/10.1080/10826084.2016.1276601.

\section{Authors}

Chenshu Zhang, Judith S. Brook, Neo K. Morojele, Mario De La Rosa, Carl G. Leukefeld, and David W. Brook 
Published in final edited form as:

Subst Use Misuse. 2017 August 24; 52(10): 1328-1337. doi:10.1080/10826084.2016.1276601.

\title{
Psychosocial Factors Related to the Intergenerational Transmission of Externalizing Behaviors in Early Midlife
}

\author{
Chenshu Zhang, Ph.D. ${ }^{1}$, Judith S. Brook, Ed.D. ${ }^{1}$, Neo K. Morojele, Ph.D. ${ }^{2}$, Mario De La \\ Rosa, M.S.S.A., Ph.D. ${ }^{3}$, Carl G. Leukefeld, DSW ${ }^{4}$, and David W. Brook, M.D. ${ }^{1}$ \\ ${ }^{1}$ Department of Psychiatry, New York University School of Medicine, New York, NY 10016, USA \\ ${ }^{2}$ Alcohol, Tobacco and Other Drug Research Unit, Medical Research Council, Pretoria, South \\ Africa \\ ${ }^{3}$ Robert Stempel College of Public Health \& Social Work, Florida International University, Miami, \\ FL 33199, USA \\ ${ }^{4}$ Department of Behavioral Sciences, University of Kentucky, Lexington, KY 40506-9983, USA
}

\section{Abstract}

Introduction-To study the intergenerational transmission of externalizing behaviors.

Methods-Participants came from a community-based random sample of residents in two upstate New York counties ( $\mathrm{N}=548$ ). Data were collected from mothers at mean age 40 and from their children from adolescence (mean age $=14, \mathrm{SD}=2.8$ ) to early midlife (mean age $=43, \mathrm{SD}=$ 2.8 ) at seven time points. Structural equation modeling (SEM) was used to study the psychosocial factors as related to externalizing behaviors in early midlife.

Results-First, maternal externalizing behaviors were indirectly associated with the offspring's externalizing behaviors through the offspring's substance use in adolescence, the offspring's partner's smoking patterns, and the offspring's marital conflict. Second, maternal cigarette smoking was indirectly associated with the offspring's externalizing behaviors through the offspring's substance use in adolescence, the offspring's partner's cigarette smoking, and the offspring's marital conflict. Third, maternal marital conflict had an indirect effect on the offspring's externalizing behaviors, mediated by offspring marital conflict.

Conclusions-The finding that externalizing behaviors can be transmitted from parent to child informs the need for family-based interventions that are appropriate to adolescents.

\section{Keywords}

externalizing behaviors; intergenerational transmission; longitudinal study; substance use; marital conflict

Correspondence should be sent to Dr. Judith S. Brook, Department of Psychiatry, New York University School of Medicine, 215 Lexington Ave., $15^{\text {th }}$ Floor, New York, NY 10016, USA. Phone (212) 263-4662; Fax (212) 263-4660; judith.brook@ nyumc.org. Conflict of Interest

The authors have no conflicts of interest to report. 


\section{INTRODUCTION}

Externalizing behavior is characterized primarily by "actions in the external world, such as acting out, antisocial behavior, hostility, and aggression."(American Psychological Association, 2007) Externalizing behaviors, such as rebellion, marijuana use, low responsibility and substance use disorders, are associated with a wide array of adverse outcomes in various domains. In addition, there is significant evidence that externalizing behaviors are transmitted intergenerationally between parent and child (Bailey, Hill, Oesterle, \& Hawking, 2006; Biederman, Faraone, Monuteaux, \& Feighner, 2000; Riggs, Chih-Ping Chou, and Pentz, 2009). Therefore, it is helpful to determine the factors which put a person at high risk for developing externalizing behaviors, so efforts can be made to reduce the transmission of these behaviors across generations.

\section{Family Interactional Theory (FIT)}

Previous research and Family Interactional Theory (FIT) have demonstrated that there are a number of personal and interpersonal factors which heighten the risk of developing externalizing behaviors (XXXX, 1990). FIT is a multidimensional conceptual model, explaining the development of substance use and externalizing behavior over time by postulating a developmental sequence of influences from multiple domains on the individual's behavior. According to FIT, the primary developmental context is the family. One of the major mechanisms linking the domains within FIT is modeling. In this study, we extend this research and theoretical framework by proposing a cohesive model which brings together several of the findings discussed below and ultimately maps the interrelationships among several domains of risk factors, which have not been investigated previously. More specifically, the model based on FIT hypothesizes that maternal externalizing behaviors, maternal cigarette smoking, and maternal marital conflict are associated with the offspring's substance use in adolescence. Substance use by the adolescent predicts later partner conflict and partner cigarette smoking. Marital conflict and spouse/partner cigarette smoking are then related to the individual's own externalizing behavior in early midlife.

\section{Maternal Externalizing Behaviors}

Externalizing behaviors such as substance use and externalizing personal attributes can be transmitted across generations from parent to child (Bailey et al., 2006; Biederman et al., 2000; Riggs et al., 2009). For example, Epstein, Hill, Bailey, and Hawkins (2013) found that drug conducive family environments may predict nicotine dependence in individuals at age 33 after controlling for smoking at age 18 and having a partner who smokes. In addition to this direct effect, there are several indirect effects as well. Externalizing behaviors in parents are associated with the child's substance use during adolescence (Biederman et al., 2000; Kaplow, Curran, \& Dodge, 2002; Li, Pentz, \& Chou, 2002). Offspring who use substances in adolescence are more likely to exhibit externalizing behaviors as adults (Johnson, Boles, \& Kleber, 2000; Lai, Page, \& McCoy, 2000). For example, adolescents who smoke cigarettes or drink alcohol as adults are much more likely to indicate that they are willing to use, or have used, illicit drugs (Johnson et al., 2000; Lai et al., 2000). 
In addition, adolescents who use such substances as adults normally choose a partner with similar substance use patterns (Johnson et al., 2000; Lai et al., 2000; Meyler, Stimpson, \& Peek, 2007; Price \& Vandenberg, 1980; Vink, Willemsen, \& Boomsma, 2003). Having a partner who smokes or drinks is also a risk factor for externalizing behavior among adults in the early 40s (Moos, 2007). Lastly, substance use as an adolescent increases the likelihood of marital conflict in adulthood (Doherty \& Doherty, 1998; Fu \& Goldman, 2000). Drug use and smoking are associated with higher risks of divorce (Fu \& Goldman, 2000). One study found that adults who smoked cigarettes were 53\% more likely to have experienced divorce compared to nonsmokers (Doherty \& Doherty, 1998). In turn, experiencing marital conflict itself is directly associated with parental externalizing behaviors in adulthood (Whisman, Uebelacker, \& Bruce, 2006).

\section{Maternal Cigarette Smoking}

The cigarette smoking of the parental generation directly and indirectly contributes to a child's development of externalizing behaviors. Several investigators have found that offspring's substance use disorder can be predicted by family environments where the use of tobacco is prevalent (Bailey, Hill, Meacham, Young, \& Hawkins, 2011). In addition to this direct effect, there may be several indirect effects. For example, having a parent who smokes increases the likelihood that the child will initiate smoking (Gilman et al., 2009). This likelihood increases with the number of parents who smoke and the duration of exposure to parental smoking (Gilman et al., 2009). As noted above, substance use, including smoking, during adolescence is directly associated with externalizing behaviors in adulthood (Johnson et al., 2000; Lai et al., 2000). According to FIT, children imitate the behaviors of their parents (White, Johnson, \& Buyske, 2000). The child may model the patterns of consumption and attitude toward cigarette smoking that was observed in the parent (White et al., 2000).

In addition, maternal cigarette use is associated with the patterns of smoking observed in the adult child's partner (Heffernan \& Fraley, 2013). Heffernan and Fraley (2013) found that people reported a greater attraction to smokers if one of their parents smoked frequently while the participants were growing up (Heffernan \& Fraley, 2013). Additionally, Epstein and colleagues found continuity from the family smoking environment to the choice of a partner who smokes later in life (Epstein et al., 2013).

\section{Family Environment}

As regards the home environment, family conflict and parental marital conflict are highly correlated with adolescent drug use and general impaired adolescent functioning (Bray, Adams, Getz, \& Baer, 2001; David, Steele, Forehand, \& Armistead, 1996; Kristjansson, Logi, Sigfusdottir, Allegrante, \& Helgason, 2009; Moos, 2007; Troxel \& Matthews, 2004). Parental marital conflict also increases the likelihood that the children will experience conflict in their own marriages (Amato \& Cheadle, 2005; Amato \& DeBoer, 2001). One study suggests that this relationship can span several generations as divorce of the grandparents is related to greater marital discord of the grandchildren (Amato \& Cheadle, 2005). As stated previously, marital conflict is directly associated with ongoing adult substance abuse (Whisman et al., 2006). 
As regards partner marital conflict and partner cigarette smoking, the research suggests that both partner marital conflict and partner cigarette smoking predict adult externalizing behavior. This interpretation is in line with FIT which suggests that having a partner who smokes cigarettes may contribute to the individual's externalizing behaviors.

The present study adds to the literature in several important ways. First, none of the previous studies has investigated the relationship of all these significant areas in one comprehensive developmental model that incorporates parental and child variables beginning in adolescence and extending to the fifth decade of life. This study intends to fill this gap. Second, research in this area is often based on self-report of single informant, method that includes reports of both parent and offspring can reduce bias. This study includes both parent and offspring reports. Third, this investigation based on FIT is unique in that it uses a data set that spans a period of more than 30 years.

\section{Hypotheses}

Three specific hypotheses were tested in the present study. First, we hypothesize that maternal externalizing behaviors will have a direct effect on the offspring's externalizing behaviors as well as an effect mediated by the offspring's substance use in adolescence, the offspring's partner's smoking patterns, and the offspring's marital conflict. Second, we hypothesize that the maternal cigarette smoking will affect the offspring's externalizing behaviors directly and indirectly through the offspring's substance use in adolescence, the offspring's partner's cigarette smoking, and the offspring's marital conflict. Third, maternal marital conflict will have an effect on the offspring's externalizing behaviors mediated by the offspring's substance use in adolescence and later marital conflict (see Figure 1).

\section{METHODS}

\section{Participants and Procedure}

Data on the participants came from a longitudinal psychosocial study of mothers and their children, begun in 1975. The study is entitled, "Children and Adults in the Community." Participants were from a community-based random sample of families, residing in one of two counties, Albany or Saratoga, in upstate New York. Primary sampling units were created from enumeration districts and block groups which, when taken together, comprised the entire area of the selected counties. The primary sampling units in each county were stratified by urban/rural status, the proportion of Whites, and median family income. A systematic sample of primary sampling units in each county was then drawn with probability proportional to the number of households, and probabilities equal for members of all strata. Segments of blocks were then selected with probability proportional to size (number of households), and each was surveyed in the field with a proportion of the households being selected according to the predetermined sampling ratio. Address lists were compiled in this process, and interviewers were sent to the selected addresses. Those households with at least one child between the ages of one and ten years were qualified for the study. In each qualified household, the interviewer, by use of a set of Kish Tables (Kish, 1949), randomly selected one child from those in the appropriate age range. The sampled families were generally representative of families in the northeast U.S. at that time. For example, there was 
a close match between the participants and the 1980 U.S. Census with regard to family income, maternal education, and family structure.

The present analysis $(\mathrm{N}=548)$ is based on data from Time 2 (T2; 1983) - Time 8 (T8; 2012-2013) of this longitudinal study. Participants consisted of N=548 mother-offspring pairs. The mean age of the mother participants (G1) at $\mathrm{T} 2$ was 40.0 years ( $\mathrm{SD}=6.2)$. The offspring participants' mean ages (SDs) at the follow-up interviews were $14.1(2.8)$ at T2, $16.3(2.8)$ at $\mathrm{T} 3,22.3(2.8)$ at $\mathrm{T} 4,27.0(2.8)$ at $\mathrm{T} 5,31.9(2.8)$ at $\mathrm{T} 6,36.6(2.8)$ at $\mathrm{T} 7$, and 43.0 (2.8) at $\mathrm{T} 8$, respectively.

Extensively trained and supervised lay interviewers administered individual structured maternal interviews at $\mathrm{T} 2$ and offspring interviews at $\mathrm{T} 2-\mathrm{T} 7$ (participants were interviewed in private). Questionnaires were self-administered by offspring participants at T8. Written informed consent and HIPAA authorization were obtained from all participants. The procedures used in this research study at T7-T8 were approved by the Institutional Review Board of the New York University School of Medicine. Earlier waves of data collection at T2 were approved by the Mount Sinai School of Medicine Institutional Review Board. Additional information regarding the study methodology and measurements in varied domains are available in prior publications (e.g., XXXX, 1990; XXXX, 1996; XXXX, 2013).

\section{Measures}

The Dependent Latent Variable-The dependent variable, G2 adult offspring externalizing behaviors at $\mathrm{T} 8$, consisted of 5 scales: rebellion, delinquency, nicotine dependence, alcohol use disorder (abuse or dependence), and substance use disorder (abuse or dependence) (see Table 1 for the number of items comprising each scale, response ranges, mean, standard deviation, sample items, the scale author(s), and Cronbach's alphas).

The Independent Latent and Manifest Variables-The independent latent variables were G1 maternal externalizing behaviors at T2 (rebellion, low self-control, impulsivity, tolerance of deviance, low responsibility, marijuana use, and hard liquor use), G1 maternal marital conflict at T2 (arguments, low marital harmony, and low admiration of husband), G1 maternal cigarette smoking at T2, G2 offspring substance use at T2-T3 (cigarette smoking and marijuana use), G2 offspring marital conflict at T7 (arguments, low marital harmony, low emotional intimacy, and low satisfaction with spouse/partner), and G2 offspring spouse/ partner's cigarette smoking at T7 (see Table 1 for the number of items comprising each scale, response ranges, mean, standard deviation, sample items, the scale author(s), and Cronbach's alphas).

Control Variables-In the analyses, we statistically controlled for the following variables: the G2 offspring's gender and age in their early 40s.

Data Analysis-A latent variable confirmatory structural equation model (SEM) (Chou \& Bentler, 1995) was used to examine the empirical validity of the hypothesized pathways. SEM is a multivariate statistical method that evaluates both the measurement quality of a set of variables used to assess a latent construct (the measurement model) and the relationships 
among the latent constructs (the structural model). To account for the influences of the offspring's gender and age at T8 on these models, we used a partial correlation matrix as the input matrix. This was created by statistically partialing out (removing the effect of) the baseline measure of the variables cited above on each of the original manifest variables in the present analyses. Our proposed model was estimated using Mplus (Muthén \& Muthén, 2010). The Mplus (Muthén \& Muthén, 2010) default option was used (i.e., full information maximum likelihood approach; FIML) to treat missing data. The advantage of FIML is that the results are less likely to be biased even if the data are not missing completely at random (Muthén, Kaplan, \& Hollis, 1987). We chose three fit indices to assess the fit of the models: (1) the root mean square error of approximation (RMSEA), (2) Bentler's comparative fit index (CFI) (Bentler, 1990), and (3) the standardized root mean square residual (SRMR). Values between .90 and 1.0 on Bentler's CFI indicate that the model provides a good fit to the data (Kelloway, 1998). Values for the RMSEA and the SRMR should be below .10 to indicate a good fit. We also calculated the standardized total effects, which equal the sum of the direct and the indirect effects of each latent or manifest variable estimated in the analysis of the dependent variable.

\section{RESULTS}

For the measurement model, all factor loadings were significant ( $p<.01)$, showing that the indicator variables were satisfactory measures of the latent constructs. The factor loading matrix for the measurement model is available from the authors upon request. The RMSEA was .046, Bentler's CFI was .91, and the SRMR was .052, and they all reflect a satisfactory model fit. The obtained path diagram along with the standardized regression coefficients and z-statistics are depicted in Figure 1.

As shown in Figure 1, the results partially supported our major hypotheses. Two major pathways follow: First, G1 maternal externalizing behavior $(b=.2, z=3.3, p<.01)$ and cigarette smoking in the early 40s (T2) $(\mathrm{b}=.11, \mathrm{z}=1.98, \mathrm{p}<.05)$ were linked with $\mathrm{G} 2$ offspring substance use in adolescence (T2-T3). Both G1 maternal cigarette smoking in the early 40s (T2) $(\mathrm{b}=.14, \mathrm{z}=2.88, \mathrm{p}<.01)$ and $\mathrm{G} 2$ offspring substance use in adolescence (T2-T3) (b=.24, $\mathrm{z}=4.17, \mathrm{p}<.001$ ) were associated with $\mathrm{G} 2$ spouse/partner smoking (T7), which, ultimately, was associated with $\mathrm{G} 2$ offspring externalizing behaviors in the early 40s (T8) (b=.17, $\mathrm{z}=2.21, \mathrm{p}<.05)$. In addition, $\mathrm{G} 2$ offspring substance use in adolescence (T2-T3) ( $\mathrm{b}=.33, \mathrm{z}=4$, $\mathrm{p}<.001$ ) was directly associated with G2 offspring externalizing behavior in the early $40 \mathrm{~s}$ (T8). Second, G1 maternal marital conflict in the early 40s (T2) (b=.1, z=2.1, p<.05) and G2 offspring substance use in adolescence $(\mathrm{T} 2-\mathrm{T} 3)(\mathrm{b}=.12, \mathrm{z}=2.08, \mathrm{p}<.05)$ were associated with G2 offspring marital conflict in the late 30s (T7), which, in turn, was associated with G2 offspring externalizing behavior in the early 40s (T8) ( $\mathrm{b}=.2, \mathrm{z}=2.72, \mathrm{p}<.01)$. In addition, G1 maternal marital conflict $(b=.35, \mathrm{z}=6.88, \mathrm{p}<.001)$ and cigarette smoking $(\mathrm{b}=.29, \mathrm{z}=2.32, \mathrm{p}<$. 05 ) were associated with G1 maternal externalizing behavior in the early 40s (T2).

\section{Standardized Total Effects}

Table 2 presents the results of the total effect analyses. Each of the latent/manifest constructs had significant standardized total effects $(\mathrm{p}<0.05)$ on $\mathrm{G} 2$ offspring externalizing behavior in 
the early 40s. Among the constructs, G2 offspring substance use at T2-T3 (adolescence) $(\beta=0.39 ; z=4.89 ; p<.001)$ had the greatest total effects on $\mathrm{G} 2$ offspring externalizing behavior in their early 40s. (See Table 2 )

\section{DISCUSSION}

The present study extends prior research by offering a unified developmental model which maps the interrelationships among a number of personal and interpersonal factors which increase the risk of developing externalizing behaviors in adulthood. More specifically, the purpose of this research was to assess whether externalizing behaviors in the offspring in early midlife were related longitudinally to both personal and/or interpersonal (maternal and spouse/partner) factors from earlier life stages. Consequently, we examined the impact of maternal externalizing behavior (e.g., marijuana use, rebellion) on the offspring's externalizing behaviors (e.g., substance use disorders, rebellion). In addition, we examined the offspring's own substance use in adolescence as related to their own later externalizing behaviors. This study is unique in that it is based on an extensive data set of mothers and their children that spans more than 30 years.

\section{Maternal Externalizing Behaviors}

Despite the temporal distance, maternal externalizing behaviors are indirectly associated with increased externalizing behavior in their adult offspring. Our findings are in accord with several previous studies which suggest that there is an intergenerational transmission of externalizing behaviors (Biederman et al., 2000; Riggs et al., 2009). FIT may contribute to explaining this association, as children may replicate the patterns of substance use and other externalizing behaviors observed in parents (XXXX, 1990). Additionally, this study provides evidence that the association between maternal externalizing behaviors and offspring externalizing behaviors was mediated by offspring substance use, offspring partner's smoking, and offspring marital conflict. Specifically, and in accordance with previous studies, the analysis supports the association between maternal externalizing behaviors and the offspring's substance use in adolescence (Kaplow et al., 2002; Li et al., 2002) and further, the association between adolescent substance use and externalizing behaviors in adulthood (Johnson et al., 2000; Lai et al., 2000). The findings also bolster the evidence for the idea that adolescents who use substances will choose a partner with similar substance use habits (XXXX, 1990; Meyler et al., 2007; Price \& Vandenberg, 1980; Vink et al., 2003), and having a partner who uses substances is a risk factor for developing externalizing behaviors in adulthood (Moos, 2007). Despite the indirect associations, our hypothesis that maternal externalizing behaviors is directly associated with externalizing behavior in their adult offspring was not supported by the data.

Selection theory may explain the finding that adolescents choose partners with similar substance use habits. This theory, part of which is incorporated in FIT, suggests that adolescents coordinate their choices of friends, and thus also partners or spouses, to maximize similarity within the pair (Kandel \& Davies, 1991). FIT may explain the association between having a partner who uses substances and the increased likelihood of developing externalizing behavior. These theories propose that new patterns of behavior are 
acquired through observing the behaviors of others (XXXX, 1990). Additionally, the current study found an association between substance use during adolescence and marital conflict during the late 30s. This is supported by a study which posits that drug use and smoking are correlated with higher risks of divorce (Fu \& Goldman, 2000). In turn, marriages where there is a great deal of conflict put offspring participants at a higher risk for developing externalizing behaviors in adulthood (Whisman et al., 2006).

\section{Maternal Cigarette Smoking}

Consistent with the importance of powerful distal effects, the analysis provides support for an association between maternal smoking and externalizing behaviors in their offspring. The findings suggest an indirect effect mediated by G2 substance use and G2 partner smoking. As demonstrated in previous studies, having a parent who smokes increases the likelihood that the child will use cigarettes in adolescence (Gilman et al., 2009). This relationship may be explained by FIT which suggests that offspring often imitate the patterns of substance use observed in their parents (XXXX, 1990). Additionally, a relationship between maternal substance use patterns and the offspring's partner's substance use patterns was observed and is supported by previous research which suggests that adult children find partners more attractive if they are similar to their parents (Geher, 2000). Consistent with the literature, adolescent substance use was associated with externalizing behaviors in adulthood (Johnson et al., 2000; Lai et al., 2000). Screening programs for substance use given to individuals in late adolescence could assist in identifying those at risk to receive appropriate cessation treatment, and enter cessation programs where possible.

\section{Maternal Marital Conflict}

Consistent with our prediction, maternal marital relations were associated with the offspring's relations with one's partner. More specifically, low parental conflict predicted the quality (e.g. emotional intimacy, marital harmony) of one's relations with one's partner. These findings are in accord with FIT and are consistent with research focused on family interactional patterns (Leveridge, Stoltenberg, \& Beesley, 2005) and with research focused on the intergenerational transmission of marital conflict (Amato \& Cheadle, 2005; Amato \& DeBoer, 2001; Troxel \& Matthews, 2004). As stated above, marital conflict is associated with offspring externalizing behavior (Whisman et al., 2006).

Interestingly, we did not find an association between maternal marital conflict and adolescent substance use. The literature provides conflicting evidence regarding the validity of this relationship. On the one hand, a review conducted by Troxel and Matthews (2004) suggests that children who grow up in high-conflict homes are more likely to use cigarettes. On the other hand, a study done by Kristjansson and colleagues (2009) found that the relationship between parental divorce and adolescent smoking was insignificant when controlling for the individual's relationship with parents, disruptive social changes and family conflict. Kristjansson and colleagues (2009) measured cigarette use in the last 30 days while Troxel and Matthews (2004) drew on longitudinal and cross-sectional studies in their review. This difference in the length of time each study was conducted may have contributed to the disparity in their results. Overall, further research should consider the long term effects of parental marital relations on externalizing behaviors in the adult offspring. 
From a practical perspective, the results indicate that prevention programs for externalizing behavior should address parental externalizing behaviors, marital conflict and cigarette smoking to prevent externalizing behavior in the offspring.

\section{Strengths and Limitations}

This study has a few limitations. First of all, the sample is comprised of primarily Whites; therefore our findings may not be generalizable to other races or ethnicities. Nevertheless, the use of a relatively homogeneous sample contributes to the potency of the internal validity of the research as it reduces bias. Secondly, these results are derived from self-report data (reported by the G1 and G2 offspring participants for their own behaviors), which can be subject to bias. Although the self-reported tobacco measure used in this study is relatively reliable, it may not fully represent the extent to which the individual uses tobacco. Third, a few of our measures, such as impulsivity and responsibility, had low Cronbach's alphas. Nevertheless, studies have found that these measures generally have satisfactory item total correlations and adequate test-retest validity (Boer, Hodgetts, \& Hodgetts, 2008; Megargee, 2009; Names deleted to protect the integrity of the review process, 1990). Despite these limitations, this study has several strengths. This research uses a relatively large communitybased sample. The current study is based on a data set that spans more than 30 years, one of a few of its kind. Therefore, it is possible to time-order variables, which is an aspect that cross-sectional studies cannot address. This is also one of a few studies to consider the interrelationships between various factors (e.g. maternal and spouse marital conflict, and maternal marijuana use and other externalizing behaviors) which may increase the likelihood of developing externalizing behaviors in the offspring in a single comprehensive model.

\section{Conclusions and Implications}

Overall, this study suggests that there are multiple pathways by which offspring may develop externalizing behaviors in adulthood. Given that externalizing behaviors are associated with many adverse outcomes, it is advantageous to investigate the factors which increase the risk for developing such behaviors so steps may be taken to reduce the incidence of externalizing behaviors. The model suggested in this study may contribute to prevention programs by advising teachers and health care providers to provide support to adolescents with parents who exhibit externalizing behaviors, parents who have conflictual relation with their partners, and parents who smoke cigarettes, as these children may be at higher risk of developing externalizing behaviors. The finding that externalizing behaviors are transmissible, that is, have continuity between parents and their offspring, informs the need for family-based interventions that are appropriate to adolescents. Additionally, parenting programs delivered through schools or community-based avenues can involve educating parents on their behavioral patterns which may foster externalizing behaviors in their offspring. Armed with this knowledge, parents may become more aware of how their actions can affect their offspring and observe significant externalizing behaviors and which behaviors to watch as their children reach adolescence. 


\section{Acknowledgements}

This research was supported by NIH grant the National Cancer Institute, awarded to from the National Institute on Drug Abuse and from review of this manuscript.

\section{Definitions of Key Terms}

\section{Externalizing behavior}

Externalizing behavior is characterized primarily by "actions in the external world, such as acting out, antisocial behavior, hostility, and aggression.

\section{Family Interactional Theory (FIT)}

A multidimensional conceptual model, explaining the development of substance use and externalizing behavior over time by postulating a developmental sequence of influences from multiple domains on the individual's behavior.

\section{Structural equation modeling (SEM)}

A multivariate statistical method that evaluates both the measurement quality of a set of variables used to assess a latent construct (the measurement model) and the relationships among the latent constructs (the structural model).

\section{FIML}

Full information maximum likelihood

\section{RMSEA}

Root mean square error of approximation

\section{CFI}

Comparative fit index

\section{SRMR}

Standardized root mean square residual

\section{References}

Amato PR, DeBoer DD. The transmission of marital instability across generations: Relationship skills or commitment to marriage? Journal of Marriage and Family. 2001; 63(4):1038-1051. DOI: 10.1111/j.1741-3737.2001.01038.x

Amato PR, Cheadle J. The long reach of divorce: Divorce and child well-being across three generations. Journal of Marriage and Family. 2005; 67(1):191-206. DOI: 10.1111/j. 0022-2445.2005.00014.x

American Psychological Association. APA Dictionary of Psychology. Author; Washington, DC: 2007.

Anthony JC, Warner L, Kessler R. Comparative epidemiology of dependence on tobacco, alcohol, controlled substances, and inhalants: Basic findings from the National Comorbidity Survey. Experimental and Clinical Psychopharmacology. 1994; 2(3):244-268. DOI: 10.1037/1064-1297.2.3.244

Bailey JA, Hill KG, Oesterle S, Hawkins JD. Linking substance use and problem behavior across three generations. Journal of Abnormal Child Psychology. 2006; 34(3):263-282. DOI: 10.1007/ s10802-006-9033-Z 
Bailey JA, Hill KG, Meacham MC, Young SE, Hawkins JD. Strategies for characterizing complex phenotypes and environments: General and specific family environmental predictors of young adult tobacco dependence, alcohol use disorder, and co-occurring problems. Drug and Alcohol Dependence. 2011; 118(2):444-451. DOI: 10.1016/j.drugalcdep.2011.05.002 [PubMed: 21636226]

Bentler PM. Comparative fit indexes in structural models. Psychological Bulletin. 1990; 107(2):238246. DOI: 10.1037/0033-2909.107.2.238 [PubMed: 2320703]

Biederman J, Faraone SV, Monuteaux MC, Feighner JA. Patterns of alcohol and drug use in adolescents can be predicted by parental substance use disorders. Pediatrics. 2000; 106(4):792-797. DOI: 10.1542/peds.106.4.792 [PubMed: 11015524]

Boer DP, Hodgetts S, Hodgetts A. The California Psychological Inventory-434-and 260 item editions. The SAGE Handbook of Personality Theory and Assessment. 2008; 2:97-112.

Bray JH, Adams GJ, Getz JG, Baer PE. Developmental, family, and ethnic in influences on adolescent alcohol usage: A growth curve approach. Journal of Family Psychology. 2001; 15(2):301-314. DOI: 10.1037/0893-3200.15.2.301 [PubMed: 11458635]

Chou, C-P., Bentler, PM. Estimates and tests in structural equation modeling. In: Hoyle, RH., editor. Structural Equation Modeling: Issues and Applications. SAGE publications; Newbury, CA: 1995. p. 37-55.

David C, Steele R, Forehand R, Armistead L. The role of family conflict and marital conflict in adolescent functioning. Journal of Family Violence. 1996; 11(1):81-91. DOI: 10.1007/ BF02333341

Doherty EW, Doherty WJ. Smoke gets in your eyes: Cigarette smoking and divorce in a national sample of American adults. Families, Systems, \& Health. 1998; 16(4):393-400. DOI: 10.1037/ h0089864

Donovan JE, Jessor R. Structure of problem behavior in adolescence and young adulthood. Journal of Consulting and Clinical Psychology. 1985; 53(6):890-904. DOI: 10.1037/0022-006X.53.6.890 [PubMed: 4086689]

Epstein M, Hill KG, Bailey JA, Hawkins JD. The effect of general and drug-specific family environments on comorbid and drug-specific problem behavior: A longitudinal examination. Developmental Psychology. 2013; 49(6):1151-1164. DOI: 10.1037/a0029309 [PubMed: 22799586]

$\mathrm{Fu} \mathrm{H}$, Goldman N. The association between health-related behaviors and the risk of divorce in the USA. Journal of Biosocial Science. 2000; 32(01):63-88. https://www.ncbi.nlm.nih.gov/pubmed/ 10676060. [PubMed: 10676060]

Geher G. Perceived and actual characteristics of parents and partners: A test of a Freudian model of mate selection. Current Psychology. 2000; 19(3):194-214. DOI: 10.1007/s12144-000-1015-7

Gilman SE, Rende R, Boergers J, Abrams DB, Buka SL, Clark MA, Niaura RS. Parental smoking and adolescent smoking initiation: An intergenerational perspective on tobacco control. Pediatrics. 2009; 123(2):e274-e281. DOI: 10.1542/peds.2008-2251 [PubMed: 19171580]

Gough, HG. The California Psychological Inventory. Consulting Psychological Press; Palo Alto, CA: 1957.

Heffernan ME, R. Fraley C. Do early caregiving experiences shape what people find attractive in adulthood? Evidence from a study on parental age. Journal of Research in Personality. 2013; 47(4):364-368. DOI: 10.1016/j.jrp.2013.03.003

Jessor, R., Graves, TD., Hanson, RC., Jessor, SL. Society, Personality, and Deviant Behavior: A Study of a Tri-Ethnic Community. Holt, Rinehart \& Winston; New York, NY: 1968.

Johnson PB, Boles SM, Kleber HD. The relationship between adolescent smoking and drinking and likelihood estimates of illicit drug use. Journal of Addictive Diseases. 2000; 19(2):75-81. DOI: 10.1300/J069v19n02_06 [PubMed: 10809521]

Johnston, LD., O’Malley, PM., Bachman, JG., Schulenberg, JE. Secondary School Students.;684. Monitoring the Future National Survey Results on Drug Use, 1975-2005. Vol. Vol 1. National Institute on Drug Abuse; Bethesda, MD: 2006. NIH Publication No. 06-5883

Kandel D, Davies M. Friendship networks, intimacy, and illicit drug use in young adulthood: A comparison of two competing theories. Criminology. 1991; 29(3):441-469. DOI: 10.1111/j. 1745-9125.1991.tb01074.x 
Kaplow JB, Curran PJ, Dodge KA. Child, parent, and peer predictors of early-onset substance use: A multisite longitudinal study. Journal of Abnormal Child Psychology. 2002; 30(3):199-216. DOI: 10.1023/A:1015183927979 [PubMed: 12041707]

Kelloway, EK. Using LISREL for Structural Equation Modeling. Sage; Thousand Oaks, CA: 1998.

Kessler RC, McGonagle KA, Zhao S, Nelson CB, Hughes M, Eshleman S, Kendler KS. Lifetime and 12-month prevalence of DSM-III-R psychiatric disorders in the United States: Results from the National Comorbidity Survey. Archives of General Psychiatry. 1994; 51(1):8-19. DOI: 10.1001/ archpsyc.1994.03950010008002 [PubMed: 8279933]

Kessler RC, Nelson CB, McGonagle KA, Edlund MJ, Frank RG, Leaf JP. The epidemiology of cooccurring mental disorders and substance use disorders in the National Comorbidity Survey: Implications for service utilization. American Journal of Orthopsychiatry. 1996; 66(1):17-31. DOI: 10.1037/h0080151 [PubMed: 8720638]

Kish, Leslie. A procedure for objective respondent selection within the household. Journal of the American Statistical Association. 1949; 44(247):380-387. DOI: 10.1080/01621459.1949.10483314

Kristjansson AL, Sigfusdottir ID, Allegrante JP, Helgason AR. Parental divorce and adolescent cigarette smoking and alcohol use: Assessing the importance of family conflict. Acta Paediatrica. 2009; 98(3):537-542. DOI: 10.1111/j.1651-2227.2008.01133.x [PubMed: 19021591]

Lai S, Lai H, Page JB, McCoy CB. The association between cigarette smoking and drug abuse in the United States. Journal of Addictive Diseases. 2000; 19(4):11-24. DOI: 10.1300/J069v19n04_02

Leveridge M, Stoltenberg C, Beesley D. Relationship of attachment style to personality factors and family interaction patterns. Contemporary Family Therapy. 2005; 27(4):577-597. DOI: 10.1007/ s10591-005-8243-9

Li C, Pentz MA, Chou C-P. Parental substance use as a modifier of adolescent substance use risk. Addiction. 2002; 97(12):1537-1550. DOI: 10.1046/j.1360-0443.2002.00238.x [PubMed: 12472638]

Megargee EI. The California Psychological Inventory. Oxford Handbook of Personality Assessment. 2009:323-335.

Meyler D, Stimpson JP, Peek MK. Health concordance within couples: A systematic review. Social Science \& Medicine. 2007; 64(11):2297-2310. DOI: 10.1016/j.socscimed.2007.02.007 [PubMed: 17374552]

Moos RH. Theory-based processes that promote the remission of substance use disorders. Clinical Psychology Review. 2007; 27(5):537-551. doi: 10.1016\%2Fj.cpr.2006.12.006. [PubMed: 17254686]

Muthén B, Kaplan D, Hollis M. On structural equation modeling with data that are not missing completely at random. Psychometrika. 1987; 52(3):431-462. DOI: 10.1007/BF02294365

Muthén, LK., Muthén, BO. Mplus User's Guide. 6th ed. Author; Los Angeles, CA: 2010.

Price RA, Vandenberg SG. Spouse similarity in American and Swedish couples. Behavior Genetics. 1980; 10(1):59-71. DOI: 10.1007/BF01067319 [PubMed: 7191703]

Riggs NR, Chou C-P, Pentz MA. Protecting against intergenerational problem behavior: Mediational effects of prevented marijuana use on second-generation parent-child relationships and child impulsivity. Drug and Alcohol Dependence. 2009; 100(1):153-160. doi: 10.1016\%2Fj.drugalcdep. 2008.10.003. [PubMed: 19036535]

Smith, GE., Fogg, CP., Simmons, R. Psychological antecedents of teen-age drug use. In: Simmons, R., editor. Research in Community and Mental Health: An Annual Compilation of Research. Vol. 1. JAI Press; Greenwich, CT: 1979. p. 87-120.

Spanier GB. Measuring dyadic adjustment: New scales for assessing the quality of marriage and similar dyads. Journal of Marriage and the Family. 1976; 38(1):15-28. DOI: 10.2307/350547.

Troxel WM, Matthews KA. What are the costs of marital conflict and dissolution to children's physical health? Clinical Child and Family Psychology Review. 2004; 7(1):29-57. DOI: 10.1023/B:CCFP. 0000020191.73542.b0 [PubMed: 15119687]

Vink JM, Willemsen G, Boomsma DI. The association of current smoking behavior with the smoking behavior of parents, siblings, friends and spouses. Addictio. 2003; 98(7):923-931. DOI: 10.1046/j. 1360-0443.2003.00405.x 
Whisman MA, Uebelacker LA, Bruce ML. Longitudinal association between marital dissatisfaction and alcohol use disorders in a community sample. Journal of Family Psychology. 2006; 20(1): 164-167. DOI: 10.1037/0893-3200.20.1.164 [PubMed: 16569102]

White HR, Johnson V, Buyske S. Parental modeling and parenting behavior effects on offspring alcohol and cigarette use: A growth curve analysis. Journal of Substance Abuse. 2000; 12(3):287310. DOI: 10.1016/S0899-3289(00)00056-0 [PubMed: 11367605]

1990. Name deleted to protect the integrity of the review process

1996. Name deleted to protect the integrity of the review process

2013. Name deleted to protect the integrity of the review process 


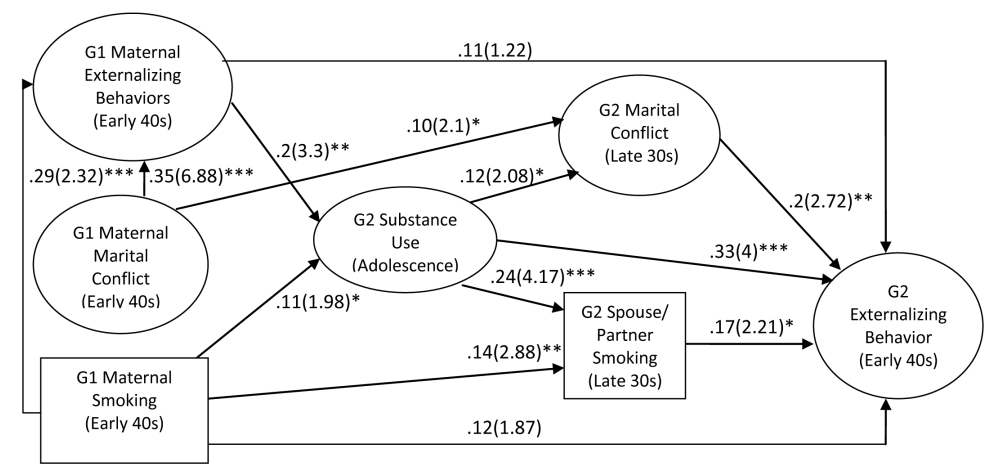

$$
\begin{aligned}
& \text { Note: } 1 \text {. RMSEA }=0.046 ; \mathrm{CFI}=0.91 ; \mathrm{SRMR}=0.052 ; \\
& \text { 2. } \mathrm{G} 1=\text { generation } 1 \text { mother; } \mathrm{G} 2=\text { generation } 2 \text { offspring; } \\
& \text { 3. } \mathrm{G} 2 \text { Age at } \mathrm{T} 8 \text { and gender were statistically controlled; } \\
& \text { 4. }{ }^{*} \mathrm{p}<.05 ;{ }^{*} \mathrm{p}<.01 ;{ }^{* *} \mathrm{p}<.001 .
\end{aligned}
$$

Figure 1.

Standardized Pathways (z-statistic) to Offspring Externalizing Behavior in the Early 40s $(\mathrm{N}=548)$. 


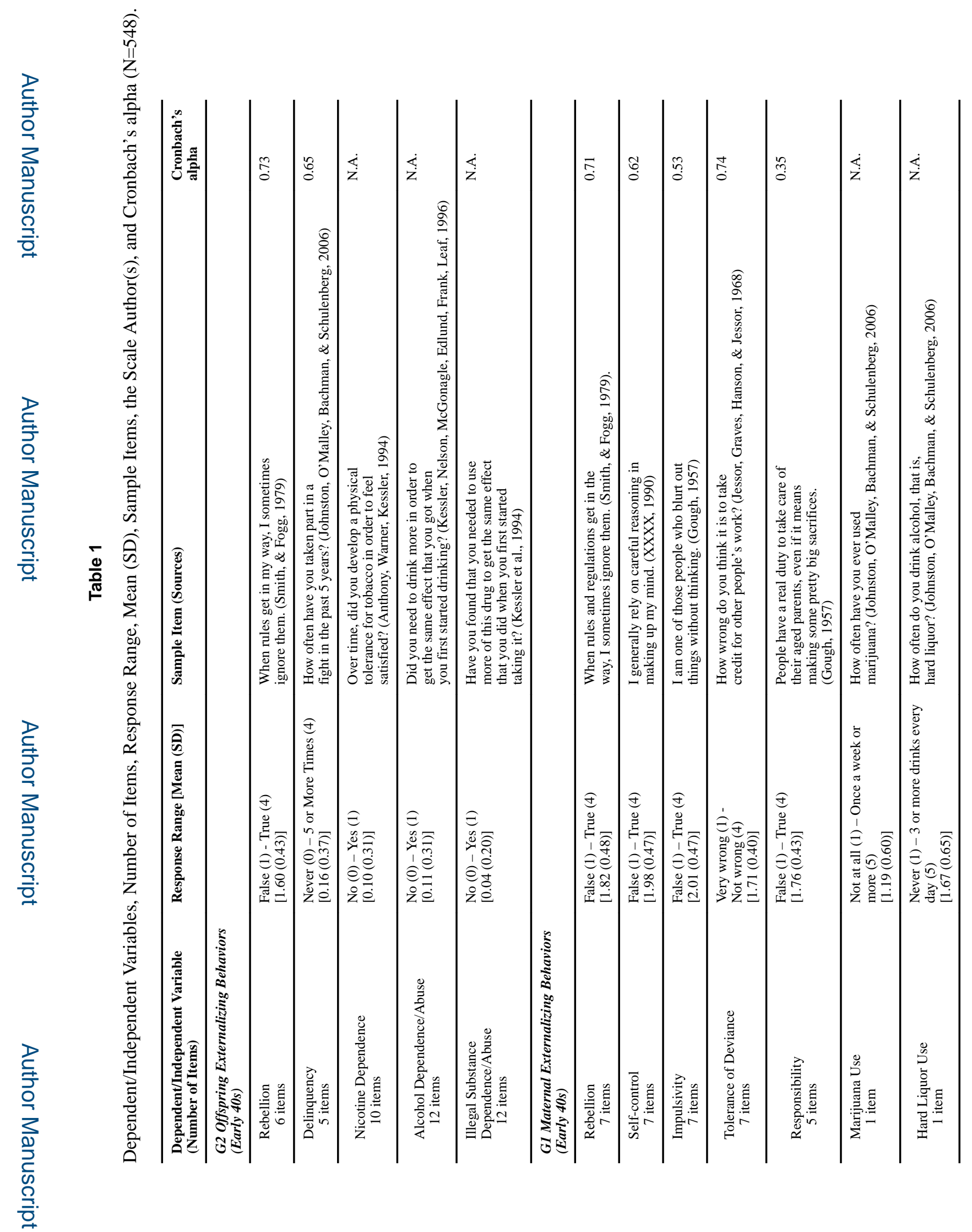

Subst Use Misuse. Author manuscript; available in PMC 2017 August 24. 
Zhang et al.

Page 16

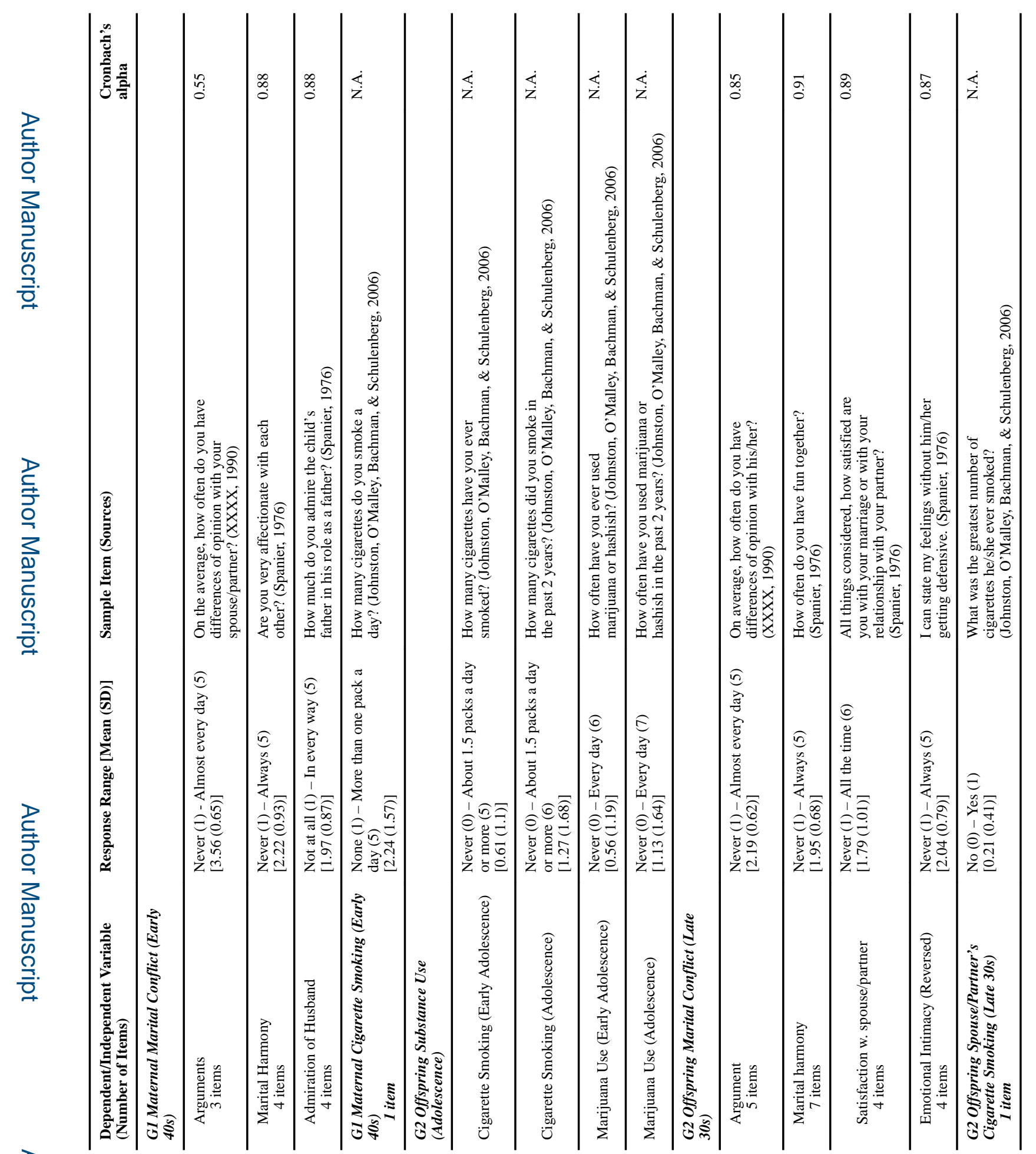

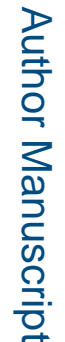

Subst Use Misuse. Author manuscript; available in PMC 2017 August 24. 


\section{Table 2}

Standardized Total Effects (z-statistic) of Independent Variables/Constructs on Offspring Externalizing Behaviors in the Early 40s ( $\mathrm{N}=548)$.

\begin{tabular}{lc}
\hline & $\begin{array}{c}\text { G2 Offspring Externalizing Behavior } \\
\text { at T8 (Early 40s) }\end{array}$ \\
\cline { 2 - 2 } Independent Manifest Variables/Latent Constructs & $\begin{array}{c}\text { Standardized Total Effects } \\
\text { (z-statistic) }\end{array}$ \\
G2 Offspring Marital Conflict at T7 (Late 30s) & $0.2(2.72)^{* *}$ \\
G2 Spouse/Partner Cigarette Smoking at T7 (Late 30s) & $0.17(2.21)^{*}$ \\
G2 Offspring Substance Use at T2-T3 (Adolescence) & $0.39(4.89)^{* * *}$ \\
G1 Maternal Externalizing Behavior at T2 (Early 40s) & $0.19(2.08)^{*}$ \\
G1 Maternal Marital Conflict at T2 (Early 40s) & $0.09(2.29)^{*}$ \\
G1 Maternal Cigarette Smoking at T2 (Early 40s) & $0.23(3.99)^{* * *}$ \\
\hline
\end{tabular}

Notes:

1. G1=generation 1 mother; G2=generation 2 offspring;

2. G2 Age at T8 and gender were statistically controlled;

3. $\quad * \mathrm{p}<.05 ; * * \mathrm{p}<.01 ; * * * \mathrm{p}<.001$. 